\title{
The Green Vistas of Sustainable Innovation in the IT Domain
}

\author{
Wietske van Osch and Michel Avital \\ University of Amsterdam, 1018WB Amsterdam, Netherlands \\ Tel.: +31(0) $205257584,+31$ (0) 205255059 \\ $\{$ W.vanOsch, Avital\} @uva.nl
}

\begin{abstract}
Sustainable innovation is about creating social, environmental, and economic value for all stakeholders involved. The sustainable innovation lens offers an extension of the prevailing discourse on Green IT/IS and renders a three-fold approach that encompasses social, environmental and economic dimensions of sustainability. Moreover, sustainable innovation entails a proactive approach that focuses on developing creative solutions to environmental and social challenges rather than merely on reducing the IT footprint by waste management and regulation compliance. Building on a longitudinal analysis of sustainable innovation in the automotive industry, we gained a number of relevant insights that can be applied to the information technology domain. First, our results illustrate that a sustainable innovation approach can serve as a source of creativity and innovation that enables firms to aim for generating bigger wins for businesses, the environment, and society overall. Second, our results suggest that sustainable innovation requires a concerted effort of all stakeholders to reshape existing norms and values, formulate new standards, and reconfigure work systems vis-à-vis the social and environmental vistas of sustainable value. Building on our study, we provide further recommendations for IT research and practice.
\end{abstract}

Keywords: Green IT, Green IS, Sustainability, Innovation.

\section{Introduction}

With the centrality of information technology and charges that it is responsible for $2 \%$ of the world's total CO2 emissions (Gartner, 2007), it is not surprising that in recent years the issue of Green IT/IS has gained momentum. Overall, so far we can identify two primary approaches to sustainability — one focuses on how to reduce the negative ecological impact of information technologies, Green IT, and the other focuses on how to leverage information technologies for solving our environmental problems, Green IS. The former approach treats information technologies as part of the problem and addresses the question of how to reduce their ecological footprint by cutting $\mathrm{CO} 2$ emissions, energy consumption, and waste throughout their lifecycle. The latter approach considers information technologies or information systems as part of the solution and analyzes their potential role in helping organizations to manage their environmental footprint. 
Notwithstanding the valuable insights that the Green IT/IS ${ }^{1}$ movements have contributed, we posit that they have largely overlooked two important issues. First, both approaches have been focused on the ecological (i.e. environmental) facet of sustainability, while falling short of noticing the significance of its social aspect. Second, Green IT/IS has been driven largely by regulation and the desire to reduce costs, while virtually disregarding the potential generative and value added capacity of sustainable innovation with respect to the prevailing technologies. Compliance with regulation and cost reduction have steered the discussion and subsequent efforts toward mitigating and managing technology's negative environmental effects through primarily reactive approaches, which have in turn led to downplaying the potential of IT/IS in fostering sustainable innovation as a source of social, environmental, and economic value for all stakeholders involved.

To that end, we propose approaching the underlying topic through the sustainable innovation lens (Cooperrider, 2008), which builds on, yet extends, the prevailing conceptions of Green IT/IS. Overall, sustainable innovation refers to designing and implementing sustainable organizational processes and practices that generate social, environmental, and economic worth for all stakeholders involved (Thatchenkery et al. 2010). Applying the sustainable innovation lens to the discourse on Green IT/IS has two appealing promises. First, it offers reframing the underlying issues with an extended approach to sustainability that addresses a range of environmental, social, and economic values in the context of information technology. Second, it redirects our attention to the importance of innovation and multi-stakeholder collaboration in proactively addressing challenges and opportunities of sustainability.

Building on analysis of sustainable innovation in the automotive industry, we draw two insights with respect to the information technology domain. First, a sustainable innovation approach can serve as a source of creativity and innovation that enables firms to generate bigger wins for the business, the environment, and society overall. Second, the study suggests that sustainable innovation requires a concerted effort by all stakeholders to reshape existing norms and values, to formulate new standards, and to reconfigure work systems for diffusing sustainable technologies.

In what follows, we first describe the prevailing IT-related context of sustainability. Then, we present the findings through a brief synopsis of sustainable innovation in the automotive industry. Finally, we apply the generated findings regarding sustainable innovation to information technology and discuss its implications for research and practice.

\section{Three Perspectives on Sustainable Information Technology}

Sustainability in the context of IT is often addressed through the narrative of Green IT (i.e. greening IT) or Green IS (i.e. greening by IT), and we offer an alternative, namely Sustainable Innovation. In this section we briefly describe the three different approaches to sustainability and juxtapose them in Table 1.

${ }^{1}$ The abbreviated term "Green IT/IS" throughout this paper denotes Green IT and Green IS. It does not imply that Green IT and Green IS are similar or interchangeable. Rather, we view Green IT and Green IS as two unique approaches and relate them separately as well as jointly to sustainable innovation. 
Table 1. Summarizing Approaches to Green and Sustainable IT/IS

\begin{tabular}{|l|l|l|l|}
\hline & Green IT & Green IS & Sustainable Innovation \\
\hline Focal Point: & IT artifact & Environment & Society \\
\hline Description: & Reducing IT footprint & $\begin{array}{l}\text { Managing environmental } \\
\text { footprint }\end{array}$ & $\begin{array}{l}\text { Generating overall sustainable } \\
\text { value for all stakeholders }\end{array}$ \\
\hline $\begin{array}{l}\text { Driver of } \\
\text { Change: }\end{array}$ & Regulation & $\begin{array}{l}\text { Costs and regulatory } \\
\text { compliance reporting }\end{array}$ & $\begin{array}{l}\text { Technical and social } \\
\text { innovation }\end{array}$ \\
\hline $\begin{array}{l}\text { Nature of } \\
\text { Change: }\end{array}$ & Reactive & Reactive/Proactive & Proactive \\
\hline $\begin{array}{l}\text { Dimensions of } \\
\text { Sustainability: }\end{array}$ & Environmental sustainability & Environmental sustainability & $\begin{array}{l}\text { Social and environmental } \\
\text { sustainability }\end{array}$ \\
\hline
\end{tabular}

\subsection{Green IT}

The bulk of the nascent literature on Green IT to date is concerned with greening IT, that is, with mitigating the negative impact of IT on energy consumption and $\mathrm{CO} 2$ emissions (Murugesan, 2008; Gartner 2007; Pernici et al., 2008). The most prominent drivers of Green IT are regulation (Mingay, 2008) and the increased concerns about the impact of IT on a company's energy spending. The research and business practice in this area aimed at eliminating waste, increasing efficiency, and lowering energy costs. Thereby, it is primarily reactive and focused on the environmental facet of sustainability.

\subsection{Green IS}

A smaller set of studies has addressed the potential role of information technology in helping organizations to manage their environmental footprint, i.e. greening by IT. This approach has been referred to as Green IS (Boudreau et al., 2008) stressing the greater potential of information systems rather than information technology in dealing with environmental management. The most prominent driver of Green IS is regulatory compliance reporting as well as the desire to reduce costs of energy and carbon emissions (Mingay, 2008). Thereby, it is also primarily reactive and focused on the environmental facet of sustainability.

\subsection{Sustainable Innovation}

Taking an affirmative holistic stance, sustainability can be seen as "a business approach to creating long-term shareholder and stakeholder value by embracing opportunities and risks derived from economic, environmental and social developments" (Dow Jones Sustainability Group). Hence, generating environmental, social, and economic sustainability is not perceived as a burden for businesses, but rather as an innovation challenge, a strong differentiator, and a potential source of competitive advantage (Cooperrider, 2008, Laszlo, 2008). Sustainable innovation draws on the intrinsic motivation of companies to take responsibility for all stakeholders, future generations, and the environment itself. It stresses the crucial role businesses can play in creating a sustainable world when acting as a source of innovation and creativity to address sustainability-related challenges in a holistic manner. Additionally, sustainable innovation highlights the importance of multi-stakeholder innovation-e.g., of 
collective engagements among businesses, governments, educational institutions, and the community-for generating sustainability. In short, the sustainable innovation approach provides a wider and inclusive boundary-spanning outlook on the underlying subject matter (see Table 1).

\section{Findings}

In what follows, we briefly explore some general findings regarding sustainable innovation in the automotive industry over the past two decades. Building on our generalized observations regarding the potential benefits of adopting the sustainable innovation approach in the context of information technology, the subsequent section provides insights for both IT research and IT practice. Sustainable innovation holds that companies can take a proactive role in solving sustainability-related challenges only if they look beyond regulation compliance and cost reduction, and subsequently search for opportunities to shape legislation, to create value for the community and all stakeholders, and to rethink and redesign unsustainable products, processes, and entire systems.

The generated findings clearly reflect this proactive and collaborative nature of sustainable innovation in the automotive industry. First, the study shows that the development and successful diffusion of technologies is highly dependent on a sequence of contingencies including technical, economic, regulatory, social, and environmental junctures. Second, the successful diffusion of new technological innovation depends on how well a company links the innovation to the expectations and demands in the broader social environment. Hence, sustainable innovation could succeed only when important players in the automotive industry were able to understand and rethink the unsustainable nature of existing processes and systems and to proactively search for sustainable alternatives that appeal to their respective markets.

For example, the great success of hybrid vehicles, in particular Toyota's Prius, and at the same time, the failure of electric and fuel cell vehicles have not been solely based on technological considerations or performance, but also on social circumstances. The successful hybrid technology, did not require a significant disruption of existing technologies, norms, and standards, rather was it designed to use the existing technology base, such as refueling infrastructure, functional requirements, and institutional frameworks, that was already in place for traditional cars. In contrast, electric and fuel cell cars, entailed a radical discontinuity from the internal combustion engine, and called for fundamental reframing of preferences and expectations, values and norms, standards and regulations. Although electric vehicles and fuel cell cars can create environmental value and social value simultaneously, the diffusion of such sustainable alternatives has been impossible without the proper multiple complementary social and institutional measures. Therefore, sustainable innovation requires the concerted efforts of all stakeholders to change related norms, formulate new standards, alter prevailing preferences, and reshape dominant practices for opening up paths to sustainable innovation. 


\section{Discussion and Conclusion}

Sustainable innovation requires a broad and inclusive view of the underlying issues with a long-range perspective that is rooted in historical depth. Just as management is an instance of governance, green IT can be seen as an instance of sustainable innovation. In spite of the limitations to generalizing from a different industry, we propose the sustainable innovation approach as an extension of the current Green IT/IS frameworks. Sustainable innovation redirects our efforts to the creation of sustainable environmental, social, and economic value, and does not limit our actions to environmental concerns. Moreover, it offers an augmented perspective by focusing on creating positive solutions to environmental and social challenges through multistakeholder collaboration rather than on reducing and managing the IT footprint.

In what follows, we apply the accumulated insights regarding sustainable innovation in the car industry to information technology, and discuss how it can shed light on the challenges and opportunities ahead.

\subsection{Implications and Recommendations for IT Research}

Sustainable innovation, as introduced in this paper, can serve as a rhetorical device that can extend the Green IT/IS discourse far beyond ecological considerations. Adopting the sustainable innovation lens would provide researchers with the leverage necessary to elevate their research beyond environmental sustainability into a wider context relating to innovation and society; for instance, by studying how companies, through their IT innovation efforts, can contribute to sustainability, diversity, human rights, employee relations, safe and clean products, as well as good governance structures. Furthermore, by relying on sustainable innovation, researchers can look for ways in which contemporary social and global challenges can be turned into business opportunities and how innovation can be used for generating a sustainable world. This implies not only adopting a broader perspective on sustainability—by incorporating its three pillars - but also a wider approach to innovation-by acknowledging the need for collaborative engagements between businesses and society.

\subsection{Implications and Recommendations for IT Practice}

Our observations can also provide insights into the practice of sustainable use and application of IT, which seems to leave much room for improvement according to watchdog groups who monitor the situation. For instance, Greenpeace's 2009 Guide to Greener Electronics indicates that only a few companies in the IT industry have made an effort to become greener and that most companies perform unsatisfactorily ${ }^{2}$. Overall, new information technologies and systems will be able to generate more environmental and social value for stakeholders only if the current efforts that focus on incremental and reactive innovation programs (such as the reduction of energy consumption and waste disposal) will be reinforced with more radical technological innovations that reshape current practices and reconfigure existing work systems.

\footnotetext{
${ }^{2}$ http://www.greenpeace.org/international/campaigns/toxics/electronics/how-the-companiesline-up
} 
Moreover, our findings show that creating sustainable information technology is likely to require multi-stakeholder involvement. The IT industry, let alone a single organization, is unlikely to drive successfully a significant change or manage the sustainable challenge single-handedly, using the leverage of technological innovation. Instead, leading companies and the IT industry as a whole should seek involvement of the public, interest groups, universities, non-profit organizations, and government agencies.

Finally, our results indicate that merely responding to social and economic factors that trigger needs for more sustainable technologies is unlikely to be sufficient for reshaping the extraordinary potential of information technology in creating significant sustainable value. Rather, applying the sustainable innovation approach, companies need to adopt a leading role in shaping radical new technologies that provide environmental, social and economic value for all stakeholders involved and in reshaping the respective societal and institutional frameworks.

\section{References}

Boudreau, M., Watson, R.T., Chen, A.: From Green IT to Green IS. Cutter Benchmark Review 8(5), 5-11 (2008)

Cooperrider, D.: Sustainable Innovation. BizEd, 32-37 (2008)

Gartner Research, Gartner Symposium/ITxpo 2007: Emerging Trends, Gartner Inc. (2007)

Laszlo, C.: Sustainable Value. In: How the World's Leading Companies Are Doing Well by Doing Good. Greenleaf Publishing, Sheffield (2008)

Mingay, S.: Green IT: The New Industry Shock Wave. In: Gartner, Green IT Grand Conference, vol. 7 (2008)

Murugesan, S.: Harnessing Green IT: Principles and Practices. IT Professional 10(1), 24-33 (2008)

Pernici, B., Ardagna, D., Cappiello, C.: Business Process Design: Towards Service-based Green Information Systems. In: SSME Cross Session in IFIP World Computer Congress, vol. 280, pp. 195-203 (2008)

Thatchenkery, T., Cooperrider, D., Avital, M.: Positive Design and Appreciative Construction: From Sustainable Development to Sustainable Value. Advances in Appreciative Inquiry Series, vol. 4. Emerald Publishing, Bingley (2010) 